\title{
Processing and characterization of laser-sintered $\mathrm{Al}_{2} \mathrm{O}_{3} / \mathrm{ZrO}_{2} / \mathrm{SiO}_{2}$
}

\author{
Wei Wang • Sha Ma • J. Y. H. Fuh • L. Lu • Yongxian Liu
}

Received: 25 June 2012 / Accepted: 24 February 2013 / Published online: 14 March 2013

(C) The Author(s) 2013. This article is published with open access at Springerlink.com

\begin{abstract}
In this study, bioceramics of alumina, zirconia, and silica were synthesized through Nd:YAG laser sintering process aiming at studying the microstructure and phase composition based on the various laser processing parameters used. Optimal parameters of scanning speed and average laser power for selective laser sintering were determined. Effect of shifting of consecutive single vector on the process of forming the monolayer was also studied. Following the synthesis, the structure and composition were characterized by scanning electron microscopy and analyzing X-ray diffraction. The results help understand the characteristics of the laser-sintered composite ceramic formed and suggested more applications in the biomedical fields in future.
\end{abstract}

Keywords Bioceramics $\cdot$ Selective laser sintering .

Microstructure

\section{Introduction}

Selective laser sintering (SLS) is one of the popular rapid prototyping processes for forming complex components with diverse material properties from metal, plastic, ceramic, etc. By using CAD/CAM, three-dimension arbitrary-shaped components can be produced through additive laminated-material process without special dies and tools. Accordingly, flexible fabrication method can reduce the design time and total cost. Theoretically, any heated powders which are bonded together

\footnotetext{
W. Wang $(\bowtie) \cdot$ Y. Liu

School of Mechanical Engineering and Automation, Northeastern University, Shenyang 110819 Liaoning, People's Republic of China

e-mail: wangwei_neu@126.com

W. Wang $\cdot$ S. Ma $\cdot$ J. Y. H. Fuh $\cdot$ L. Lu

Department of Mechanical Engineering, National University of Singapore, Singapore 117576, Singapore
}

can be used as raw materials for SLS. The kinds of raw materials have covered polymers, ceramics, metal powders, and their composite powders. SLS technology has a wide range of applications and also is highly focused by industries owing to SLS process superiority such as widely available materials, suitable for multi-purpose and no-support forming process, no dies [1-4].

Ceramics are now becoming a possible alternative to the common metallic implant materials for acetabular cup implants and dental scaffolds. Since, the ceramic materials are biocompatible and more wear resistant in comparison to other metal alloys. Furthermore, alumina and silica as biomaterials are widely used in dental applications [5-9]. Many researchers studied the zirconia toughed by alumina [10-16]. The introduction of zirconia into the $\mathrm{Al}_{2} \mathrm{O}_{3}$-based composition can improve the bioceramic toughness. Ader [8] applied selective laser melting to manufacture ceramic slurry but crack formation during solidification appeared. Liu [17] processed ceramic parts based on the SLS process with acid binder.

Improvements in the SLS of bioceramics at the National University of Singapore produced specimens without posttreatment and any binder. This study is aiming at obtaining optimal laser process parameters and confirms the best patch of the biomaterials. Furthermore, phase structure and composition changes before and after laser sintering showed the transformation $\mathrm{ZrO}_{2}$ phase in the composition, and in particular characterization of biomaterial microstructures.

\section{Experimental procedure}

SLS was carried out on a laser machine consisting of a pulsed Nd:YAG laser, SL600 series laser and a self-designed and built powder layering device. The Nd:YAG laser has a maximal continuous power of $60 \mathrm{~W}$ with a wavelength of $1,064 \mathrm{~nm}$, and can be focused to a diameter of $0.1 \mathrm{~mm}$. The laser beam path moved over the powder surface according to the product's 


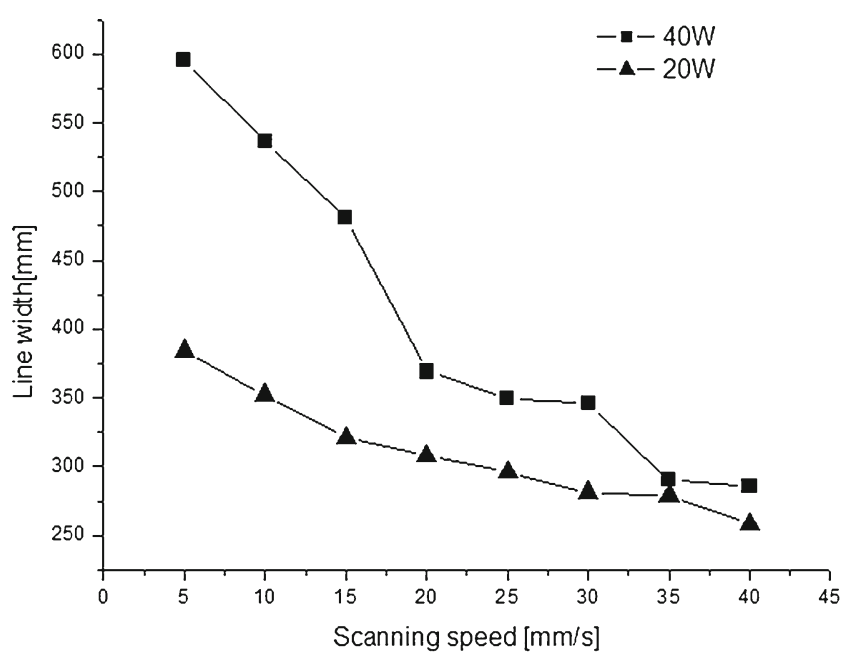

Fig. 1 Width of laser sintering vectors of the monolayer at 20 and $40 \mathrm{~W}$, respectively

cross-section or by following a predefined 2D pattern using an $\mathrm{XYZ}$ table. In this experiment, the main parameters were chosen.

Materials for SLS were prepared using $\mathrm{Al}_{2} \mathrm{O}_{3}$ (Merck, $99 \%$ ), $\mathrm{ZrO}_{2}$ (Alfa, $99 \%$ ) and $\mathrm{SiO}_{2}$ (Merk, $60.08 \mathrm{~g} / \mathrm{mol}$ ). Three patches of powder mixture of $60 \% \mathrm{Al}_{2} \mathrm{O}_{3} / 20 \% \mathrm{ZrO}_{2} / 20 \% \mathrm{SiO}_{2}$ (AZS 1), $50 \% \mathrm{Al}_{2} \mathrm{O}_{3} / 30 \% \mathrm{ZrO}_{2} / 20 \% \mathrm{SiO}_{2}$ (AZS2), and $40 \% \mathrm{Al}_{2} \mathrm{O}_{3} / 30 \% \mathrm{ZrO}_{2} / 30 \% \mathrm{SiO}_{2}(\mathrm{AZS} 3)$, corresponding to the eutectic composition, were dry milled in Fritsch planetary ball mill machine for $6 \mathrm{~h}$ prior to forming parts. After ball milling the powders were sieved using a 75-mesh sieve.

Phase present in the milled powder as well as partially and fully reaction-bonded samples were analyzed by a SHIMADZU X-ray diffraction 6000 (Cu K $\alpha$ radiation). For analyzing microstructure, the optical microscope (KEYENCE VH-Z450) and scanning electron microscopy (S-4300) incorporating energy-dispersive X-ray analysis were adopted.

\section{Results and discussion}

\subsection{Optimizing laser process parameters}

\subsubsection{Effect of laser power on sintering single vector of monolayer}

Figure 1 compares the width of laser sintering vectors of the monolayer respectively at the average laser output power of 20 and $40 \mathrm{~W}$ and different scanning speeds from 5 to $40 \mathrm{~mm} / \mathrm{s}$ with a step of $5 \mathrm{~mm} / \mathrm{s}$. It is observed clearly that the existence of continuous vectors and non-continuous vectors at two different laser powers. Figure 2 reveals the morphologies of SLS powder at different scanning speeds under 20- and 40-W laser power. It is clear that stable molten pool was formed at $40 \mathrm{~W}$ below the scanning speed of $15 \mathrm{~mm} / \mathrm{s}$. When the scanning speed is higher than $20 \mathrm{~mm} / \mathrm{s}$, discontinuity of the melting pool is obvious. Continuous vectors are sintered at the speed from 10 to $25 \mathrm{~mm} / \mathrm{s}$ at the power value of 40 and $20 \mathrm{~W}$. It is obvious that for the given laser output power, the temperature and the volume of the molten powders are higher at lower scanning speeds. It is also known that surface tension coefficient as well as melting viscosity decrease with temperature. Thus, a higher laser power lowers surface tension making the sintering vector on a series of individual droplets. The increase of the melt volume and the decrease of the
Fig. 2 Optical microscope of laser sintering monolayer at a $20 \mathrm{~W}$ and $\mathbf{b} 40 \mathrm{~W}$, respectively

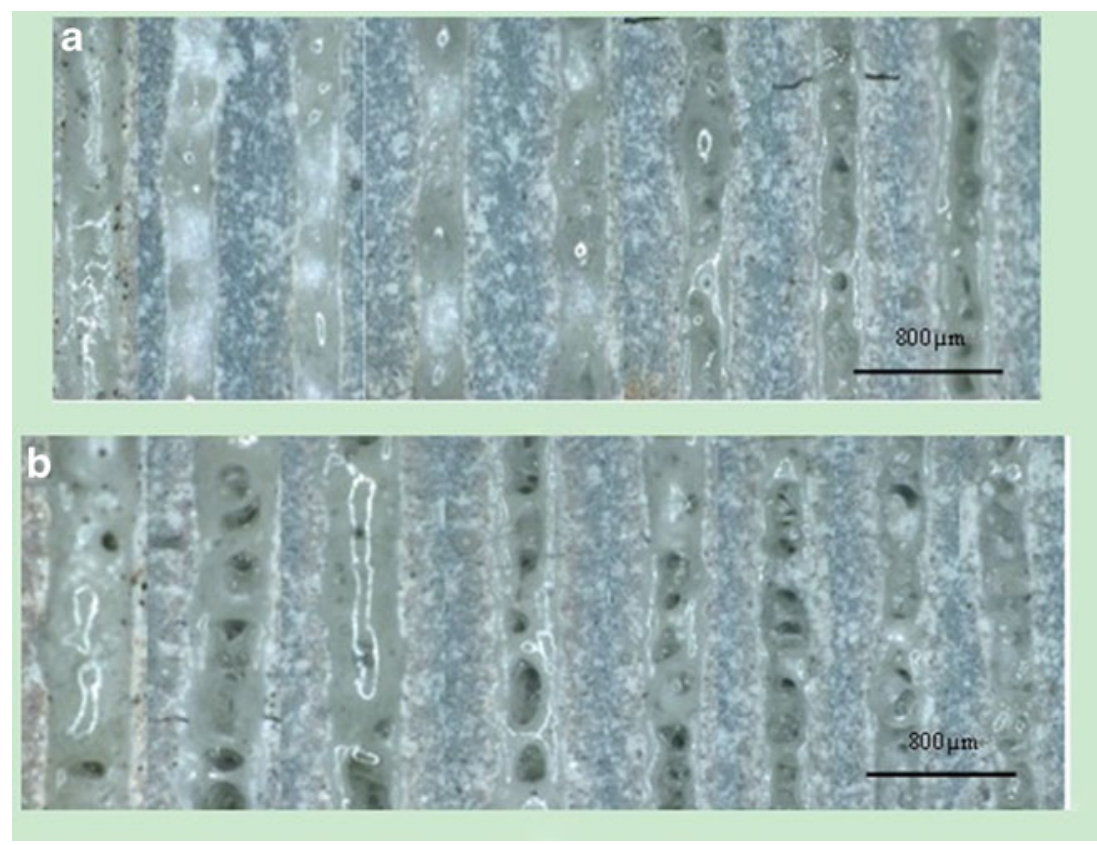


melt viscosity due to the decrease of scanning speed results in heat affected zone larger and molten vectors irregular.

It is shown that sintering chemical compounds at different laser power led to the formation of different patterns of the single vector. In the range of the studied laser parameters, desirable quality of single vector was formed by choosing at $P=40 \mathrm{~W}, V=15 \mathrm{~mm} / \mathrm{s}$, and $20 \mathrm{~mm} / \mathrm{s}$, while at $P=$ $20 \mathrm{~W}, V=15 \mathrm{~mm} / \mathrm{s}$, and $20 \mathrm{~mm} / \mathrm{s}$.

\subsubsection{Effect of single-vector hatching density on sintering the monolayer}

In order to obtain the best quality of sintered parts, optimal laser process parameters must be determined. When the value of scanning speed is constant, the appropriate laser power can improve the quality of sintering. In accordance with the results of the previous studies, the laser scanning speed is fixed at $15 \mathrm{~mm} / \mathrm{s}$. In the process of increasing laser power from 30 to $40 \mathrm{~W}$, the surface layer is found dense sintered; while the laser power attained to $50 \mathrm{~W}$, the layer seemed to be over sintering. Over sintering due to high temperature or long sintering time makes the final product quality deterioration. The dimensions of over-sintered parts do not meet the requirement and a few bubbles exit in the interior of the parts. The liquid phase (glass phase) which widens the grain boundaries, leads to the abnormal growth of crystals and mixing with the enriched grain boundary and results in the decrease of the binding force between grains. Figure 3 depicts the optical microscope at different laser power under the composite microstructure and sintered powder layer morphology. At a low laser power of $30 \mathrm{~W}$, the laser energy is not high enough to melt most of the powders. Therefore it cannot form a good dense layer as

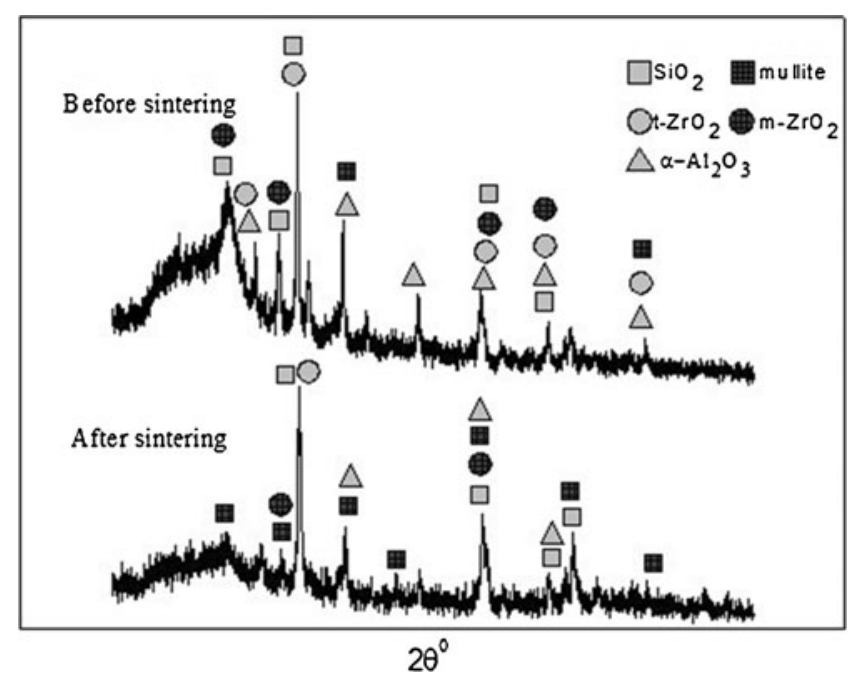

Fig. 4 X-ray diffraction spectra before and after laser sintering

shown as in Fig. 3a. With increasing laser power to $40 \mathrm{~W}$, the powder was fully melted. When the laser power is increased to $50 \mathrm{~W}$, the melting pool is too large. The absorbed powder at the edge of the melting pool during the process of the solidification will cause overburning, shown in Fig. 3c. Therefore, in order to obtain a good quality part the value of the laser power is identified as $40 \mathrm{~W}$.

\subsection{Microstructure}

Because of the close relation between the properties and the microstructure, much work has been focused on the processing of bioceramics in order to modify the microstructure and enhance the material properties so as to control the proportion and morphology of composite materials. The
Fig. 3 The optical microscope image of sintered layer under different laser output power, at a laser power $20 \mathrm{~W}$, b laser power $40 \mathrm{~W}$, and $\mathbf{c}$ laser power $50 \mathrm{~W}$
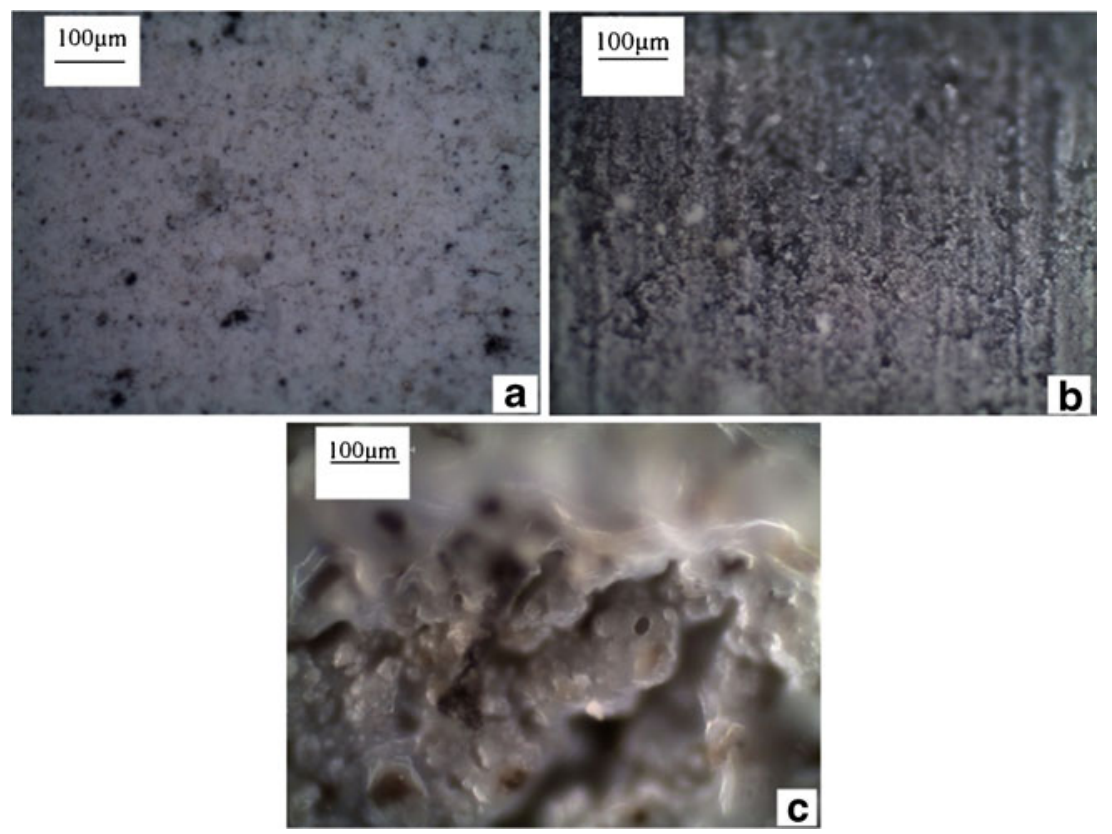
Fig. 5 SEM micrographs of three patches; surface of a AZS 1 at scanning speed $20 \mathrm{~mm} / \mathrm{s} \mathrm{b}$ AZS2 at scanning speed $20 \mathrm{~mm} / \mathrm{s}, \mathbf{c}$ AZS3 at scanning speed $20 \mathrm{~mm} / \mathrm{s}$, and $\mathbf{d}$ AZS3 scanning speed $15 \mathrm{~mm} / \mathrm{s}$
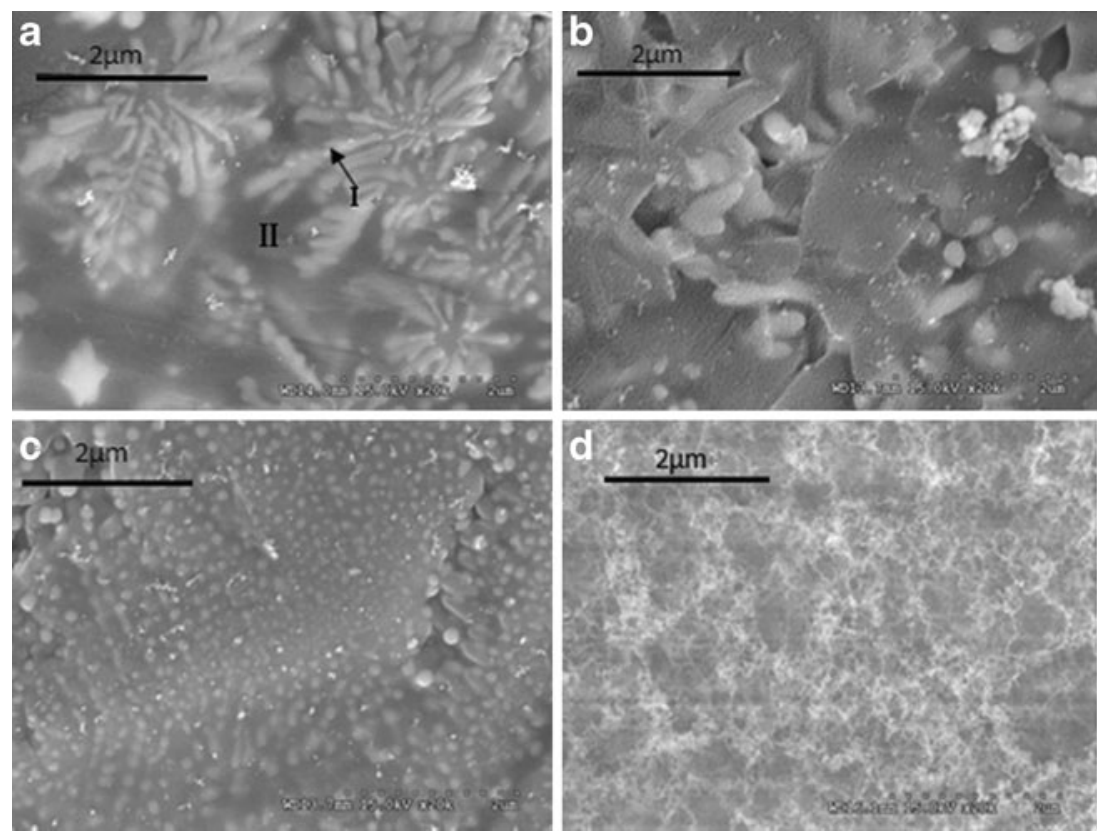

composition of main chemical content after sintering has changed from monoclinic zirconia $\left(\mathrm{m}-\mathrm{ZrO}_{2}\right)$ towards tetragonal zirconia $\left(\mathrm{t}-\mathrm{ZrO}_{2}\right)$ and condrum $\left(\alpha-\mathrm{Al}_{2} \mathrm{O}_{3}\right)$ to mullite with some residuals of starting materials as shown in Fig. 4. The use of $\mathrm{SiO}_{2}$ additions plays an important role in forming a liquid phase during the sintering. After sintering, the melted silica, particles bridge other particles together to build an interconnective porous structure. Furthermore, the amorphous silica also acts as a stabilizer rather than the binder.

The high dispersed silica phase provides mullitization with corundum rather than between $\alpha$-alumina and quartz. The mullite ceramic has excellent properties with high melting point, low thermal expansion, chemical inertness, especially slight increase with mechanical properties at high temperatures. However, mullite is also proved to be biomaterial [18]. The mullite, especially the mullite needles, should promote the mechanical stability of the samples [19].

The microstructure investigation of the chemical composition indicated that some special phenomenon during the reaction of laser sintering process was found. The characteristics of the microstructures of AZS1, AZS2, and AZS3 are shown in Fig. 5a-c. The less silica content in AZS1 and AZS2 leads to a less liquid-phase volume. The microstructure of AZS1 material is always constituted by lengthened and crossbinding grains of mullite. The examination of the ternary
$\mathrm{Al}_{2} \mathrm{O}_{3}-\mathrm{ZrO}_{2}-\mathrm{SiO}_{2}$ phase diagram [20] revealed that for the two studied compositions the first phase which crystallization are zirconia and mullite, as a result the embedding of a large proportion of zirconia particles in the mullite grains. These intragranular zirconia particles are more numerous in AZS3 than AZS1 owing to the higher zirconia content in the original AZS3 material. In the AZS2 materials, mullite grains are less lengthened as shown in Fig. $5 \mathrm{~b}$.

The dendrite-like microstructure of mullite particles leads to a improving of the fracture properties and a higher proportion of transgranular fracture mode which leads to an increase of the fracture energy. The fracture toughness properties can be increased to some extent by studying a series of fibrous microstructures with changing aspect proportions.

To further confirm the influence of scanning speed to the biomaterials, this study focused on the phase structure and composition changes. The microstructures of different speeds are presented in Fig. 6a, b. Figure 6 describes the different areas by energy-dispersive X-ray (EDX) test at higher scanning speed, $20 \mathrm{~mm} / \mathrm{s}$. The content of main elements in the white area (I) was 24.05Al-5.12Zr-14.23Si-56.600 (in wt\%) as shown in Fig. 5a while the black area (II) was $21.00 \mathrm{Al}-$ $5.86 \mathrm{Zr}-17.53 \mathrm{Si}-49.15 \mathrm{O}$ (in $\mathrm{wt} \%$ ). It is noticeable that the increase in the content of two elements ( $\mathrm{Si}$ and $\mathrm{Zr}$ ) as shown in Fig. 6 and a decrease in the content of Al. The non-uniform distribution of main elements resulted from the fast scanning
Fig. 6 EDX spectrum of the dendrite-like phase: a the white area in Fig. 4 and $\mathbf{c}$ the black area in Fig. 5 a

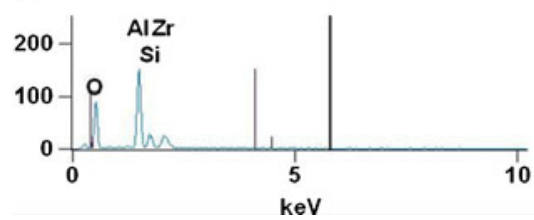

b

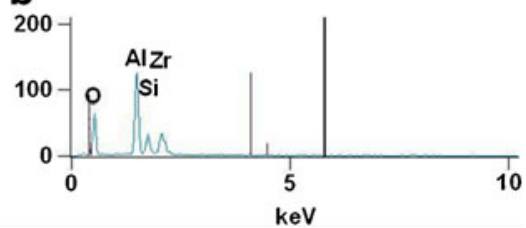


speed. However at the speed of $15 \mathrm{~mm} / \mathrm{s}$, the obtained scanning electron microscopy (SEM) images shown in Fig. 5d revealed the particles distribute uniformly. Furthermore, three main elements also conformed to the raw materials proportion and the different areas tested by EDX shows the main content are nearly same. With the optimal scanning speed, the interlayer bonding strength and the mechanical strength of the whole components can be improved. Bonding agents can be uniformly distributed and the strength of the specimens can be enhanced with the scanning speed of $15 \mathrm{~mm} / \mathrm{s}$.

\section{Conclusions}

By characterizing the laser process parameters for the bioceramic powder with the size less than $1 \mu \mathrm{m}$, the optimal parameters of the scanning speed and average laser power were identified as $15 \mathrm{~mm} / \mathrm{s}$ and $40 \mathrm{~W}$. This paper studied different proportions of bioceramics, AZS1, AZS2, and AZS3, and obtained the optimal material compositions. The microstructure of the AZS1 and AZS2 showed dendrite-like phase. In comparison of the results of before and after laser sintering shows that the SLS process transformed tetragonal zirconia to a monoclinic form. Thus, the composition of AZS3 has better material properties than that of AZS1 and AZS2. At the slower scanning speed, the uniform composition was obtained.

Acknowledgments The authors would like to acknowledge the experimental supports from the National University of Singapore (NUS) and the China Scholarship Council (CSC)'s financial support to conduct this research at NUS.

Open Access This article is distributed under the terms of the Creative Commons Attribution License which permits any use, distribution, and reproduction in any medium, provided the original author(s) and the source are credited.

\section{References}

1. Klocke F, Ader C (2003) Direct laser sintering of ceramics. Solid Freeform Fabr Symp 447-455
2. Glardon R, Karapatis N, Romano V (2001) Influence of Nd:YAG parameters on the selective laser sintering of metallic powders. CIPR Ann Manuf Technol 50(1):133-136

3. Hongjun L, Zitian F, Naiyu H, Xuanpu D (2003) A note on rapid manufacturing process of metallic parts based SLS plastic protype. J Mater Process Technol 142:710-713

4. Tang Y, Fuh JYH, Loh HT, Wong YS, Lu L (2003) Direct laser sintering of a silica sand. Mater Des 24:623-629

5. Pascal Bizot MD, Laurent Sedel MD (2001) Alumina bearings in hip replacement: theoretical and practical aspects. Oper Tech Orthop 11(4):263-269

6. Chevalier J, Gremillard L (2009) Ceramic for medical applications: a picture for the next 20 years. J Eur Ceram Soc 29:1254-1255

7. Kokubo T, Ito S, Sakka S (1986) Formation of a high-strength bioactive glass-ceramic in the system $\mathrm{MgO}-\mathrm{CaO}-\mathrm{SiO}_{2}-\mathrm{P}_{2} \mathrm{O}_{5}$. J Mater Sci 21:536-540

8. Gahler A, Heinrich JG (2006) Direct laser sintering of $\mathrm{Al}_{2} \mathrm{O}_{3}-\mathrm{SiO}_{2}$ dental ceramic components of layer-wise slurry deposition. J Am Ceram Soc 89(10):3076-3080

9. Momete D, Vitale-Brovarone C, Bretcanu O, Verne E (2006) Preparation and investigation of a glass in the system $\mathrm{Al}_{2} \mathrm{O}_{3}-$ $\mathrm{SiO}_{2}-\mathrm{CaO}$ for dental applications. Mater Lett 60:3045-3047

10. Piconi C, Maccauro G, MuratorII F, Brach Del Pever E (2003) Alumina and zirconia ceramics in joint replacements. J Appl Biomater Biomech 1:19-32

11. Ben Abdallah A, Treheux D (1991) Friction and wear of ultrahigh molecular weight polyethylene against various new ceramics. Wear 142:43-56

12. Mandrino A, Eloy R, Moyen B, Lerat J-L, Treheux D (1992) Based alumina ceramics with dispersoids: mechanical behavior and tissue response after in vivo implantation. J Mater Sci MaterMed 3:457-463

13. Salomoni A, Tucci A, Esposito L, Stamenkovich I (1994) Forming and sintering of multiphase bioceramics. J Mater Sci Mater Med 5:651-653

14. Nicoletto G, Tucci A, Esposito L (1996) Fracture and wear response of an alumina-zirconia composite. Sil Ind 20:1925-1929

15. Affatato S, Testoni M, Cacciari GL, Toni A (1990) Mixed-oxides prosthetic ceramic ball heads. Biomaterials 20:1925-1929

16. Willmann G, Früh HJ, Pfaff HG (1996) Wear characteristics of sliding pairs of zirconia(Y-TZP) for hip endoprosthese. Biomaterials 17 (22):2157-2162

17. Liu ZH, Nolte JJ, Packard JI, Hilmas G, Dogan F, Leu MC (2007) Proceedings of the 35th international matador conference 14:351-354

18. Goddridge RD, Wood DJ, Ohtsuki C, Dalgarno KW (2007) Biological evaluation of an apatite-mullite glass-ceramic produced via selective laser sintering. Acta Biomater 3:221-231

19. Moya JS, Osendi MI (1983) Effect of $\mathrm{ZrO}_{2}$ (ss) in mullite on the sintering and mechanical properties of mullite $/ \mathrm{ZrO}_{2}$ composites. $\mathrm{J}$ Mater Sci Lett 2:599-601

20. Creca MC, Emilliano JV, Segadães AM (1992) Revised phase equilibrium relastionships in the system $\mathrm{Al}_{2} \mathrm{O}_{3}-\mathrm{ZrO}_{2}-\mathrm{SiO}_{2}$. J Eur Ceram Soc 9:271-283 